\title{
Sea turtle population estimates incorporating uncertainty: a new approach applied to western North Atlantic loggerheads Caretta caretta
}

\author{
Paul M. Richards ${ }^{1, *}$, Sheryan P. Epperly ${ }^{1}$, Selina S. Heppell ${ }^{2}$, Rachel T. King ${ }^{3}$, \\ Christopher R. Sasso ${ }^{1}$, Felix Moncada ${ }^{4}$, Gonzalo Nodarse ${ }^{4}$, Donna J. Shaver ${ }^{5}$, \\ Yosvani Medina ${ }^{4}$, Julio Zurita ${ }^{6}$ \\ ${ }^{1}$ National Marine Fisheries Service, Southeast Fisheries Science Center, 75 Virginia Beach Drive, Miami, Florida 33149, USA \\ ${ }^{2}$ Department of Fisheries and Wildlife, 104 Nash Hall, Oregon State University, Corvallis, Oregon 97331, USA \\ ${ }^{3}$ Southeast Environmental Research Center, Florida International University, 11200 SW 8th Street, \\ OE-148, Miami, Florida 33199, USA \\ ${ }^{4}$ Centro de Investigaciones Pesqueras, 5ta Ave y 248, Barlovento, Ciudad Habana, Cuba \\ ${ }^{5}$ National Park Service, Padre Island National Seashore, PO Box 181300, Corpus Christi, TX 78480, USA \\ ${ }^{6}$ Comité de Protección de Tortugas Marinas en Quintana Roo, Hermosillo 26-104. Col. Roma Sur, O6760 México, D.F.
}

\begin{abstract}
Loggerhead sea turtles Caretta caretta have been listed as threatened under the US Endangered Species Act since 1978, and a change in their listing status to endangered was recently under consideration. Estimates of adult population size are needed to evaluate population status, but include a number of uncertainties. A point estimate of loggerhead population size based on a nest count fails to convey the range of our uncertainty in the estimated number of individuals in a population. We developed distributions of adult female loggerhead subpopulation sizes for 5 subpopulations of the western North Atlantic, and for the western North Atlantic population as a whole. Distributions were derived by re-sampling from available nest counts (2001-2010) and data on breeding interval, survival and clutch frequency, each affecting the extrapolation of nest numbers to adult females. Our best estimate for the western North Atlantic adult female loggerhead population was 38334 ( $\mathrm{SD}=2287$ ) adult females. Confidence limits on estimates for the individual subpopulations ranged from a high of 45058 adult females for Peninsular Florida to a low of 258 adult females in the Dry Tortugas. To reduce uncertainty in population estimates, research needs to focus on quantifying breeding interval and clutch frequency, especially in the less-studied subpopulations.
\end{abstract}

KEY WORDS: Sea turtle $\cdot$ Population size $\cdot$ Bootstrap $\cdot$ Extrapolation $\cdot$ Conservation $\cdot$ Caretta caretta $\cdot$ Loggerhead

Resale or republication not permitted without written consent of the publisher

\section{INTRODUCTION}

Loggerhead sea turtles Caretta caretta have been listed as 'threatened' under the US Endangered Species Act since 1978 (USFWS \& NMFS 1978). Loggerheads are distributed worldwide and may be divided into 9 distinct population segments (US Department of the Interior \& US Department of Commerce 2010).
Potentially the largest nesting aggregation is the western North Atlantic loggerhead population, which has subsequently been described as being divided into at least 5 subpopulations (TEWG 2009), and further subdivision may be warranted (Shamblin et al. 2010). Because of strong nest site fidelity among females, which leads to genetic differentiation and a lack of immigration, the smaller of these subpopula- 
tions may have a high risk of extinction. From 1998 to 2006, nest counts of the largest of the 5 designated subpopulations (Peninsular Florida) declined by $50 \%$ (TEWG 2009, Witherington et al. 2009). However, recent nest counts for that subpopulation have increased, and are now at levels seen in the early part of the decade (Florida Fish and Wildlife Conservation Commission unpubl. data). There was an urgent need for a thorough evaluation of population status to determine whether a change in listing for the species, from 'threatened' to 'endangered', was necessary for management (US Department of the Interior \& US Department of Commerce 2010).

Sea turtles are not often seen, except when they come on beaches to nest, or when they are either captured in fisheries or stranded onshore (TEWG 2009). There has been a good effort to monitor nesting in the USA and through much of the Northwest Atlantic population's range, and nest number has generally been used as the primary indicator of population size (Witherington et. al. 2009). Although good nest counts exist for most of the western Atlantic loggerhead subpopulations, methods for extrapolation of these counts to adult females have not been consistent. The number of years that loggerhead females spend between nesting (interannual nesting interval, or breeding interval) and the number of nests they lay per season (clutch frequency) can vary among areas, among individuals and throughout an individual's lifetime (see Dodd 1988, Schroeder et al. 2003). Uncertainty in nest counts and extrapolation of those counts to the adult population has not been thoroughly considered in past assessments. A simple estimate of adult female population size based on point estimates of clutch frequency and breeding interval fails to convey the range of variability and uncertainty around that estimate. Estimates of population size that do not take into account the variability in the underlying parameters give a false sense of confidence and, in population assessments, tend to underestimate the probability of extinction (Morris \& Doak 2002). Estimates of the number of adult females in each subpopulation are vital to effective management and for prioritizing conservation efforts on those subpopulations most in danger of extinction (Morris \& Doak 2002, NMFS \& USFWS 2008). The challenge is to estimate population size in a consistent way that takes into account the variability and uncertainty in the parameters that contribute to those estimates.

We have estimated distributions of adult female loggerhead subpopulation sizes for the 5 subpopulations of the western North Atlantic using a re- sampling technique that acknowledges the uncertainty in parameters used for conversion of nest counts to adult females. We re-sampled from data available from the literature and nesting beach observations to create confidence intervals around our estimates of subpopulation sizes. These estimates can be used in the evaluation of population status and potential effects of anthropogenic mortality.

\section{MATERIALS AND METHODS}

\section{Adult female population estimation}

Our population estimation technique was designed to incorporate uncertainty in the parameters used to extrapolate nests to adult females. As in previous studies, we estimated current subpopulation sizes of adult female loggerhead sea turtles for each subpopulation: adult females = (nests/ clutch frequency) $\times$ (survival-adjusted breeding interval), modified from TEWG (2007). We used the bootstrapped mean nest count of the last $10 \mathrm{yr}$ (2001 to 2010; Table 1) in each subpopulation for the 'nests' term to create a conservative set of estimates. We assumed that annual nest counts were a complete census with no error and that $10 \mathrm{yr}$ of nest data captures the breeding interval of even the most infrequent breeder. We acknowledge that in practice all nests are not counted and thus our data are minimal counts of nests. Then we resampled from the available data on clutch frequency and breeding interval, calculated the mean survival adjusted breeding interval (Frazer 1984), and estimated the number of adult females using the equation above. The western North Atlantic population of adult females was estimated as the sum of each of the subpopulations. Distributions of adult females were generated based on 100000 resamples of available data for each subpopulation.

\section{Subpopulations}

We used the definitions of the western North Atlantic loggerhead subpopulations described by the recent Loggerhead Turtle Expert Working Group (TEWG 2009): (1) Northern USA subpopulation (Florida/Georgia border and northwards); (2) Peninsular Florida subpopulation (Florida/Georgia border south through Pinellas County, Florida); (3) Northern Gulf of Mexico subpopulation (Franklin County, Florida, through Veracruz, Mexico); (4) Dry Tortugas 
Table 1. Caretta caretta. Estimated number of nests from beach census counts in the western North Atlantic population of loggerhead sea turtles by subpopulation and year. Greater Caribbean data, except for Quintana Roo, Mexico and Cuba, are based on SWOT (2006-2007), and add a fixed 255 nests per year. The Cay Sal Bank, Bahamas, estimate added a fixed 500 nests per year to the Dry Tortugas subpopulation

\begin{tabular}{|c|c|c|c|c|c|c|c|c|c|c|}
\hline \multirow{2}{*}{ Subpopulation } & \multicolumn{10}{|c|}{ - Year } \\
\hline & 2001 & 2002 & 2003 & 2004 & 2005 & 2006 & 2007 & 2008 & 2009 & 2010 \\
\hline Peninsular Florida & 68610 & 62190 & 62408 & 46259 & 51831 & 49141 & 44512 & 60514 & 51458 & 72863 \\
\hline Northern USA & 3076 & 3745 & 4878 & 1435 & 4204 & 4665 & 2753 & 5374 & 3620 & 5339 \\
\hline Northern Gulf of Mexico ${ }^{a}$ & 927 & 751 & 898 & 806 & 660 & 670 & 611 & 1000 & 848 & 692 \\
\hline Dry Tortugas ${ }^{\mathrm{b}}$ & 713 & 526 & 708 & 659 & 516 & 526 & 521 & 525 & 632 & 697 \\
\hline Greater Caribbean & 2545 & 1812 & 1942 & 1571 & 1743 & 1967 & 2077 & 2768 & 2849 & 3063 \\
\hline \multicolumn{11}{|c|}{ 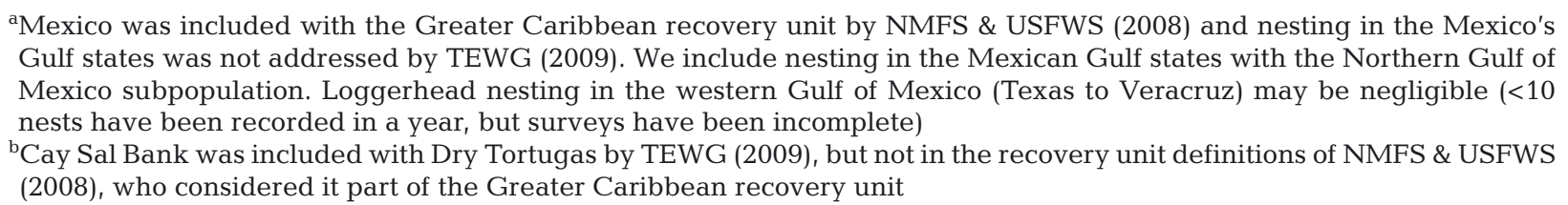 } \\
\hline
\end{tabular}

subpopulation (islands located west of Key West, Florida, and Cay Sal Bank, Bahamas); and (5) Greater Caribbean subpopulation (all other nesting assemblages within the Greater Caribbean and Mexico through French Guiana, The Bahamas, Lesser Antilles and Greater Antilles).

\section{Number of nests}

The bootstrapped mean annual number of nests was used to estimate the current population size of adult females for each subpopulation for the period 2001 to 2010 (Table 1). Nest count information was obtained from the Centro de Investigaciones Pesqueras (Cuba), Comision Nacional De Áreas Naturales Protegidas, México, Comité Estatal De Quintana Roo Para La Conservación De Las Tortugas Marinas, Padre Island National Seashore, Florida Fish and Wildlife Conservation Commission (A. Meylan pers. comm.), Georgia Department of Natural Resources (M. Dodd pers. comm.), South Carolina Department of Natural Resources (D. Griffin pers. comm.), North Carolina Wildlife Resources Commission (M. Godfrey pers. comm.), Virginia Department of Game and Fisheries (R. Boettcher pers. comm.), US Fish and Wildlife Service (D. Ingram pers. comm.) and Assateague Island National Seashore (J. Dittmar, National Aquarium pers. comm.). We assumed that many nesting beaches had a nearly complete census to estimate nest counts for each subpopulation from the years 2001 to 2010 and that there was no error reported for these counts. Known exceptions to this were in the Dry Tortugas subpopulation, and parts of the Greater Caribbean and Northern Gulf of Mexico subpopulations. The Dry Tortugas subpopulation nest counts did not include any estimates for the Cay Sal Bank, Bahamas. Based on Addison \& Morford (1996), we added 500 nests per year to the available Dry Tortugas nest count time series as a minimum estimate for Cay Sal Bank, Bahamas. Also, the Dry Tortugas proper was not surveyed in 2002 or 2005 to 2008. This gap results in a possible underestimate of approximately 100 nests per year for 2002 and 2005 to 2008. We did not attempt to compensate for this underestimate, acknowledging that it may represent a conservative bias to our subpopulation estimate, potentially as high as $8 \%$. In the Greater Caribbean there are no annual estimates available from places other than Mexico and Cuba. In Cuba, it is unlikely that all nests outside the primary nesting beaches were counted. Based on SWOT (2006 to 2007), we added 255 nests per year to the available time series as a minimum estimate for the remainder of the Caribbean. A further exception was the absence of regular surveys of remote, uninhabited barrier islands, such as those that exist throughout the range of the Northern US subpopulation. We did not attempt to estimate the number of missing nests, but we believe that the majority of nests in each subpopulation were counted; however, all nest counts must be considered minimum estimates.

\section{Clutch frequency (nests per female per season)}

Females lay multiple clutches of eggs during one nesting season. There are many sources of information on clutch frequency (see compilation by Schroeder et al. 2003) based on observations on the beach, some- 
times corrected based on inter-nesting intervals. Murphy \& Hopkins (1984) estimated clutch frequency to be 4.1 , based on the distribution of the number of nests over time and an average inter-nesting interval. Two recent studies used satellite telemetry instead of relying on repeated interception of animals on the beach. Scott (2006) deployed telemetry devices on animals nesting early in the season on barrier islands off the coast of Georgia and estimated 4.5 nests per female in the 2005 season $(n=12)$. In a similar study on Florida's southwest coast, Tucker (2010) estimated 5.5 nests per female $(\mathrm{n}=53)$. He determined that approximately half the nesting emergences occurred outside the beaches being monitored, indicating that previous estimates of clutch frequency might be biased low. Alternatively, animals that begin nesting early in the season might have a higher clutch frequency than the population average. The consequence of using an estimate that might be biased high would be to underestimate the nesting population, the most conservative approach. We bootstrapped Scott's (2006) data for the Northern US subpopulation and Tucker's (2010) data for the Peninsular Florida subpopulation to estimate a mean and variance for nests per female for these 2 subpopulations. For the Greater Caribbean we used the only available estimate of 2.45 nests per female $(\mathrm{SD}=0.031$, minimum $=2.07$, maximum $=2.84 ; \mathrm{J} . \mathrm{Zu}-$ rita unpubl. data). Because we did not have the raw data for this estimate, we used a parametric bootstrap from a stretched beta distribution (whereas a beta distribution is bounded by 0 and 1 , a stretched beta distribution is rescaled with a user defined minimum and maximum; see Morris \& Doak 2002). For the remaining subpopulations, the Northern Gulf of Mexico and the Dry Tortugas, there were no available estimates of nests per female, so we used a weighted bootstrap of the Peninsular Florida and Northern USA subpopulations, where weightings were determined by the relative nest counts.

\section{Breeding interval ('remigration')}

Breeding intervals are variable, even for a given female, and loggerheads only rarely nest in consecutive seasons (Dodd 1988, Schroeder et al. 2003). The observed intervals (Table 2) are based on recaptures of tagged females, and hence only represent turtles that survived to nest in a subsequent year. Turtles with longer intervals between nesting seasons have an inherently lower probability of surviving to nest again than turtles with a shorter breeding interval, and therefore estimates are naturally biased low. Frazer (1984) adjusted the breeding interval observed on Little Cumberland Island by his point estimate of survival in the adult population. We followed the same general procedure with the estimated breeding intervals (Table 2), adjusted by a parametric bootstrap (assuming a beta distribution) of the most recent survival estimates of 0.71 (SD = 0.014) from Melbourne Beach for the Peninsular Florida subpopulation, 0.81 (SD $=0.019)$ from Wassaw Island for the Northern USA subpopulation, and 0.85 (SD $=0.018$ ) from Mexico for the Greater Caribbean subpopulation (TEWG 2009). We used a nest count weighted bootstrap and a nest count weighted survival for the subpopulations without observed measures of breeding interval.

\section{RESULTS}

Our conservative estimate for the entire western North Atlantic population was a mean of 38334 (SD = 2287) adult females over the decade from 2001 to

Table 2. Caretta caretta. Observed breeding frequencies of loggerhead sea turtles, uncorrected for survival, by subpopulation and beach location in the western North Atlantic. Uncorrected mean breeding interval, survival-corrected mean, and standard deviations are also provided. Data sources were K. Williams (pers. comm.) for Wassaw Island (Northern USA), Bjorndal et al. (1983) for Melbourne Beach (Peninsular Florida), and J. Zurita (unpubl. data) for Quintana Roo (Greater Caribbean). Survival estimates are from TEWG (2009)

\begin{tabular}{|c|c|c|c|}
\hline $\begin{array}{ll}\text { Breeding interval } & \\
(\mathrm{yr}) & \mathrm{No} \\
& \mathrm{Wa}\end{array}$ & $\begin{array}{l}\text { orthern USA } \\
\text { assaw Island, } \\
\text { GA }\end{array}$ & $\begin{array}{c}\text { Subpopulation } \\
\text { Peninsular Florida } \\
\text { Melbourne Beach, } \\
\text { FL }\end{array}$ & $\begin{array}{c}\text { Greater Caribbean } \\
\text { Quintana Roo, } \\
\text { Mexico }\end{array}$ \\
\hline 1 & 0.02 & 0.01 & 0.09 \\
\hline 2 & 0.47 & 0.29 & 0.43 \\
\hline 3 & 0.35 & 0.37 & 0.31 \\
\hline 4 & 0.13 & 0.16 & 0.09 \\
\hline 5 & 0.03 & 0.06 & 0.04 \\
\hline 6 & 0 & 0.04 & 0.03 \\
\hline 7 & 0.01 & 0.01 & 0.01 \\
\hline 8 & 0 & 0.03 & 0 \\
\hline 9 & 0 & 0.02 & 0 \\
\hline 10 & 0 & 0.01 & 0 \\
\hline Mean & 2.85 & 2.70 & 2.63 \\
\hline \multirow{2}{*}{$\begin{array}{l}\text { Survival-corrected } \\
\text { mean (survival mean) }\end{array}$} & 3.02 & 4.24 & 2.90 \\
\hline & ) $(0.81)$ & $(0.71)$ & $(0.85)$ \\
\hline Survival-corrected & 0.13 & 0.22 & 0.06 \\
\hline SD (survival SD) & $(0.019)$ & $(0.014)$ & $(0.018)$ \\
\hline
\end{tabular}


2010. We estimated adult female subpopulation sizes to range from a minimum of 258 females for the Dry Tortugas subpopulation to a maximum of 45048 females for the Peninsular Florida subpopulation (Table 3, Fig. 1). Percentile estimates from the frequency distributions of each subpopulation estimate and for the total western North Atlantic are provided in Table 3, and can be interpreted as conservative best estimates of adult female subpopulation sizes for the last decade.

\section{DISCUSSION}

Our estimates of adult female loggerhead populations in the western North Atlantic (Table 3, Fig. 1) incorporate the uncertainty in available parameters. We interpret our estimates as the approximate population size of adult female loggerheads in the western North Atlantic over the last decade (2001 to 2010). These estimates should be useful for focusing research and conservation efforts towards those subpopulations, such as the Dry Tortugas and the Northern Gulf of Mexico, that may be perilously small. If there is little or no movement of nesting females from the larger subpopulations to the smaller ones, then these smaller subpopulations would be at much greater risk of local extinction. Furthermore, if the Florida subpopulation is more finely divided genetically than assumed in the present study (see Shamblin et al. 2010), then the risk of local extinctions may be more widespread. Even if we assume that the nests on Cay Sal Bank, Bahamas, are a part of the Dry Tortugas subpopulation, our median estimate of 331 adult females would still mean that a relatively minor local catastrophe could drive the subpopulation to extinction. Perhaps the most useful application of our method will be to more clearly quantify the relationship between nest counts as an index of population trend and the size of the adult female population.

Nest counts are the most reliable index that we have at present for sea turtle population sizes (Witherington et. al. 2009). Although we have nest counts from all loggerhead subpopulations in the western North Atlantic (Table 1), these counts underestimate the total number of nests because we are unable to collect complete counts for all subpopulations, especially non-US nest sites. We assumed that because the nest count approximations from the Caribbean outside of Cuba and Quintana Roo are currently only $8.3 \%$ of the total nests counted in the Caribbean, additional nests from non-US sites may only add a small percentage to the total count for the western North Atlantic. However, even a few additional nests could be a substantial increase for the Greater Caribbean. This is especially important because of the high genetic diversity of loggerheads in the Quintana Roo nesting assemblage (Encalada et. al. 1999). The Caribbean may have been the source of loggerheads recolonizing beaches to the north post-glaciation (Encalada et al. 1998, Bowen \& Karl 2007, but see Shamblin et al. 2010). Consistent annual nest counts for all, or at least most, of this region, together with the work already being carried out in Quintana Roo, Mexico, would go far in helping to properly assess and hopefully protect loggerheads in the Greater Caribbean, and the western North Atlantic as a whole.

An increase or decline in the number of nests from one year to the next, or even over several years, might not reflect a change in the number of adult females; therefore, running averages have been used to account for mean breeding interval when converting nest counts to population estimates (Snover \& Heppell 2009). We have done essentially the same here, using a $10 \mathrm{yr}$ time series to produce a mean and variance in nest count that captures the longest observed breeding interval of $10 \mathrm{yr}$ (see Table 2). A

Table 3. Caretta caretta. Estimated adult female population sizes for each subpopulation of loggerhead sea turtles in the western North Atlantic, and for the population as a whole (western North Atlantic). Estimates are based on nest counts from 2001 to 2010 for each subpopulation, and breeding interval, survival and clutch frequency estimates from Peninsular Florida, Northern USA and Greater Caribbean subpopulations (see 'Materials and methods' for details)

\begin{tabular}{|c|c|c|c|c|c|c|c|c|c|}
\hline \multirow{2}{*}{ Subpopulation } & \multirow[b]{2}{*}{ Min. } & \multirow[b]{2}{*}{2.5} & \multirow[b]{2}{*}{25} & \multicolumn{3}{|c|}{ Percentile of the distribution } & \multirow[b]{2}{*}{75} & \multirow[b]{2}{*}{97.5} & \multirow[b]{2}{*}{ Max. } \\
\hline & & & & 40 & 50 & 60 & & & \\
\hline Dry Tortugas & 258 & 293 & 317 & 326 & 331 & 336 & 346 & 375 & 496 \\
\hline Northern Gulf of Mexico & 323 & 379 & 413 & 425 & 432 & 440 & 452 & 493 & 634 \\
\hline Greater Caribbean & 1975 & 2275 & 2508 & 2589 & 2640 & 2690 & 2776 & 3040 & 4232 \\
\hline Northern USA & 1540 & 2369 & 2789 & 2926 & 3010 & 3090 & 3229 & 3643 & 4328 \\
\hline Peninsular Florida & 23655 & 27753 & 30353 & 31280 & 31830 & 32397 & 33376 & 36592 & 45048 \\
\hline Western North Atlantic & 30096 & 34097 & 36757 & 37686 & 38251 & 38827 & 39815 & 43056 & 51211 \\
\hline
\end{tabular}



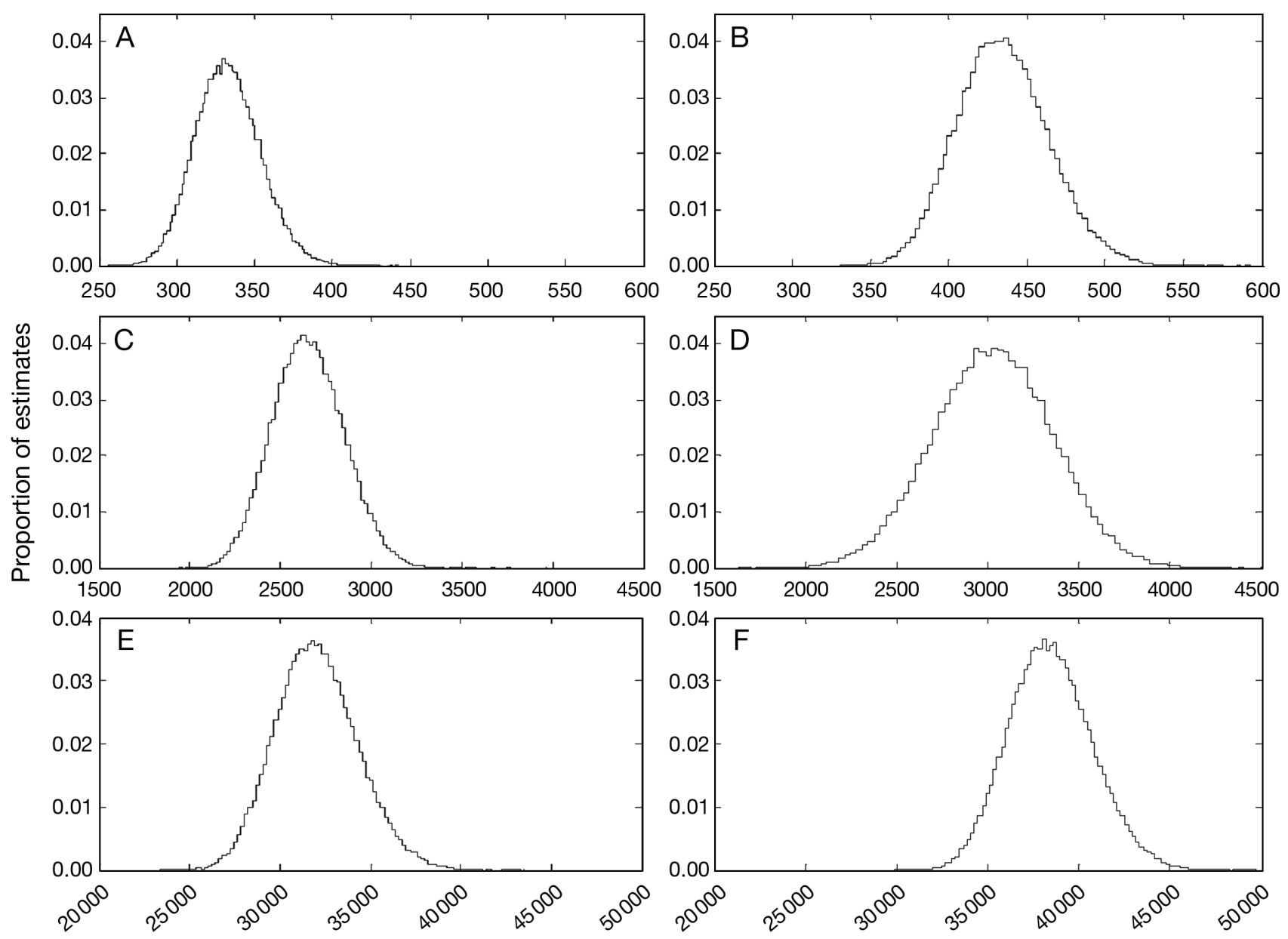

Adult female population

Fig. 1. Caretta caretta. Distributions of estimated adult female population sizes for each subpopulation of loggerhead sea turtles in the western North Atlantic, and for the population as a whole. Estimates are based on nest counts from 2001 to 2010 for each subpopulation, and breeding interval, survival and clutch frequency estimates from Peninsular Florida, Northern USA and Greater Caribbean subpopulations (see 'Materials and methods' for details). (A) Dry Tortugas, (B) Northern Gulf of Mexico, (C) Greater Caribbean, (D) Northern USA, (E) Peninsular Florida and (F) western North Atlantic

shorter time series would have been complicated by potential bias in the selection of years and because we did not have time series of any other parameters.

Implicit in our use of the 2001 to 2010 nest count time series was the assumption that there was no overall trend in nest counts during this period. Although nest counts have shown declining trends over portions of this time period for the largest subpopulation (Peninsular Florida; Witherington et al. 2009, TEWG 2009), we were not able to make population estimates for each year for any subpopulations. Nest counts can vary widely year to year because of factors other than changes in female population size (Meylan 1982, Solow et al. 2002, Van Houtan \& Halley 2011). We could not evaluate trends in the annual adult female population size using the methods pre- sented here because breeding interval and clutch frequency were not determined annually.

We relied on estimates of clutch frequency from only 3 sites and very short time periods to extrapolate to all of the subpopulations. We used only satellitetelemetry-determined clutch frequency for a subpopulation unless no estimate was available, in which case we used the traditional nocturnal-taggingdetermined values. Determining nests per female by tagging efforts has been shown to underestimate clutch frequency and thus overestimate population size (Tucker 2010). The fundamental problem of estimating clutch frequency by tagging efforts is that some nesting events during a season may not be observed because some females nest outside of the study area. A similar problem exists for estimating 
breeding interval, which may introduce an even greater bias because of the larger time frame ( 2 or more years) needed to detect a female returning to nest. Our estimates of breeding interval relied on a few studies in a few areas and over long time periods ( 20 to $30 \mathrm{yr}$ ). It seems likely that clutch frequency and breeding interval may vary substantially both spatially and temporally (Dodd 1988, Schroeder et al. 2003). Ideally, we would have independent annual estimates of all parameters (nest count, breeding interval, clutch frequency and survival) and their variation for each subpopulation.

The need for independent estimates of parameters from more locations becomes even more pressing if the western North Atlantic population is further divided into more subpopulations (as suggested by Shamblin et al. 2010). The results of the present study would not be greatly affected by such changes because we relied on the limited number of measurements from only a few sites that are currently available. If our method were to be used in the future with more spatially detailed parameter estimates, then different subpopulation boundaries could have very interesting, and possibly very large, impacts on estimates of population size and/or trends.

To improve population estimates based on nest counts, it is important to concentrate especially on improving estimates of clutch frequency and breeding interval, and on improving measures of temporal and spatial variation in those parameters. Clutch frequency would ideally be measured by satellite telemetry in each subpopulation over a number of years. Breeding interval could be estimated annually by measuring plasma steroid levels of females in foraging grounds, such as has been done for green sea turtles Chelonia mydas from southern Queensland, Australia (Hamann et al. 2002), within an intensive in-water sampling program. This method would also eliminate the additional complications of measuring breeding interval with repeated interception of animals on the beach, and adjusting breeding interval by adult female survival.

In summary, consistently collected annual nest counts for all subpopulations over a period of 15 to $20 \mathrm{yr}$ (or more), combined with consistent estimates of clutch frequency and the proportion of females nesting in each subpopulation in each year, would provide the minimum data needed to determine an annual population trend. Longer time series would be preferable, and the ideal length of time series depends upon the time to maturity for loggerheads (and possibly longer due to climate fluctuations, see Van Houtan \& Halley 2011), a parameter that needs to be estimated more rigorously to realistically estimate extinction risk for sea turtles (TEWG 2009).

Acknowledgements. We thank the following organizations for providing some of the data used in this analysis: US Fish and Wildlife Service (Diane Ingram), North Carolina Wildlife Resources Commission (Matthew Godfrey), Virginia Department of Game and Inland Fisheries (Ruth Boettcher), Georgia Department of Natural Resources (Mark Dodd), South Carolina Department of Natural Resources (DuBose Griffin), Florida Fish and Wildlife Conservation Commission (Anne Meylan), Caretta Research Project (Kristina Williams), Assateague Island National Seashore (Jack Kumer), National Aquarium (Jennifer Dittmar), Back Bay National Wildlife Refuge (John Gallegos), Chincoteague National Wildlife Refuge (Amanda Daisey) and NASA/Wallops Flight Facility (Joel Mitchell). We thank the editor and reviewers for suggestions that substantially improved the manuscript.

\section{LITERATURE CITED}

Addison DS, Morford B (1996) Sea turtle nesting activity on the Cay Sal Bank, Bahamas. Bahamas J Sci 3:31-36

Bjorndal KA, Meylan AB, Turner BJ (1983) Sea turtle nesting at Melbourne Beach, Florida, I. Size, growth, and reproductive biology. Biol Conserv 26:65-77

Bowen BW, Karl SA (2007) Population genetics and phylogeography of sea turtles. Mol Ecol 16:4886-4907

Dodd CK (1988) Synopsis of the biological data on the loggerhead sea turtle Caretta caretta (Linnaeus 1758). Biol Rep US Fish Wildl Serv 88:1-110

Encalada SE, Bjornadal KA, Bolton AB, Zurita JC and others (1998) Population structure of loggerhead turtle (Caretta caretta) nesting colonies in the Atlantic and Mediterranean as inferred from mitochondrial DNA control region sequences. Mar Biol 130:567-575

Encalada SE, Zurita JC, Bowen BW (1999) Genetic consequences of coastal development: the sea turtle rookeries at X-cacel, Mexico. Mar Turtle Newsl 83:8-10

Frazer NB (1984) A model for assessing mean age-specific fecundity in sea turtle populations. Herpetologica 40: 281-291

Hamann M, Jessop TS, Limpus CJ, Whittier JM (2002) Interactions among endocrinology, seasonal reproductive cycles and the nesting biology of the female green sea turtle. Mar Biol 140:823-830

Meylan A (1982) Sea turtle migration: evidence from tag returns. In: Bjorndal KA (ed) Biology and conservation of sea turtles. Smithsonian Institution Press, Washington, DC, p 91-100

Morris WF, Doak DF (2002) Quantitative conservation biology. Sinauer Associates, Sunderland, MA

Murphy T, Hopkins SR (1984) Aerial and ground surveys of marine turtle nesting beaches in the southeast region. Final report to the US National Marine Fisheries Service. Lamer, Green Pond, SC

NMFS (National Marine Fisheries Service) and USFWS (US Fish and Wildlife Service) (2008) Recovery plan for the northwest Atlantic population of the loggerhead sea turtle (Caretta caretta), 2nd revision. NMFS, Silver Spring, $\mathrm{MD}$ 
Schroeder BA, Foley AM, Bagley DA (2003) Nesting patterns, reproductive migrations, and adult foraging areas of loggerhead turtles. In: $\mathrm{AB}$ Bolten, BE Witherington (eds) Loggerhead sea turtles. Smithsonian Books, Washington, DC, p 114-124

Scott JA (2006) Use of satellite telemetry to determine ecology and management of loggerhead turtle (Caretta caretta) during the nesting season in Georgia. MSc thesis, University of Georgia, Athens, GA

Shamblin BM, Dodd MG, Bagley DA, Ehrhart LM and others (2010) Genetic structure of the southeastern United States loggerhead turtle nesting aggregation: evidence of additional structure within the Peninsular Florida recovery unit. Mar Biol 158:571-587

Snover ML, Heppell SS (2009) Application of diffusion approximation for risk assessments of sea turtle populations. Ecol Appl 19:774-785

Solow AR, Bjorndal KA, Bolton AB (2002) Annual variation in nesting numbers of marine turtles: the effect of sea surface temperature on re-migration intervals. Ecol Lett 5:742-746

SWOT (The State of the World's Sea Turtles) (2006-2007) A global glimpse of loggerhead nesting, Vol. II. Available at http://SeaTurtleStatus.org

TEWG (Turtle Expert Working Group) (2007) An assessment of the leatherback turtle population in the Atlantic Ocean. NOAA Tech Memo NMFS-SEFSC-555.

Editorial responsibility: Paolo Casale, Rome, Italy
Available at http://www.sefsc.noaa.gov/seaturtletech memos.jsp

TEWG (2009) An assessment of the loggerhead turtle population in the western North Atlantic Ocean. NOAA Tech Memo NMFS-SEFSC-575. Available at www.sefsc.noaa. gov/seaturtletechmemos.jsp

Tucker AD (2010) Nest site fidelity and clutch frequency of loggerhead turtles are better elucidated by satellite telemetry than by nocturnal tagging efforts: implications for stock estimation. J Exp Mar Biol Ecol 383:48-55

US Department of the Interior and US Department of Commerce (2010) Endangered and threatened species; proposed listing of nine distinct population segments of loggerhead sea turtles as endangered or threatened; proposed rule. Fed Regist 75:12598-12656

USFWS (US Fish and Wildlife Service) and NMFS (National Marine Fisheries Service) (1978) Listing and protecting loggerhead sea turtles as 'threatened species' and populations of green and olive ridley sea turtles as threatened species or 'endangered species'. Fed Regist 43: $32800-32811$

> Van Houtan KS, Halley JM (2011) Long-term climate forcing in loggerhead sea turtle nesting. PLoS ONE 6:e19043 doi:10.1371/journal.pone.0019043

Witherington B, Kubilis P, Brost B, Meylan A (2009) Decreasing annual nest counts in a globally important loggerhead sea turtle population. Ecol Appl 19:30-54

Submitted: May 10, 2011; Accepted: September 02, 2011

Proofs received from author(s): November 1, 2011 